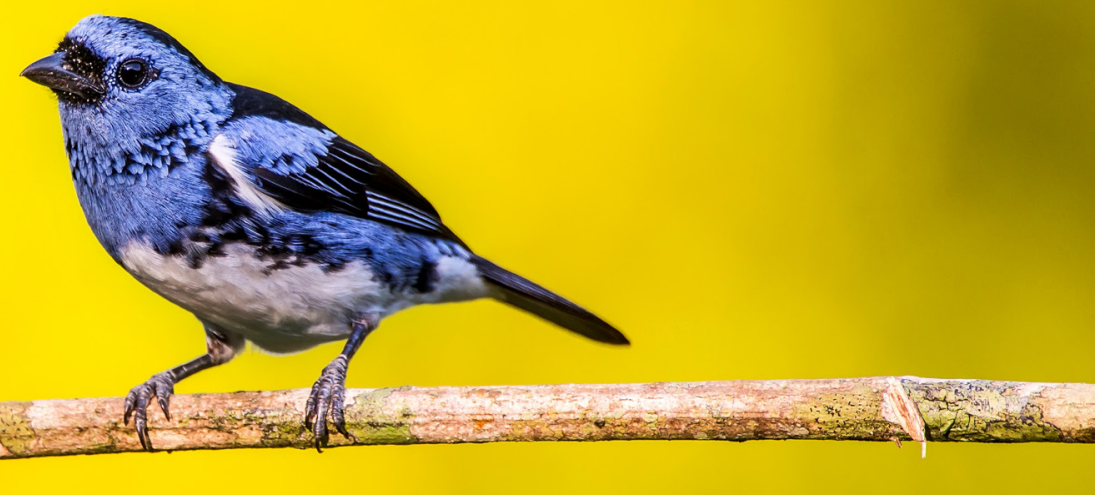

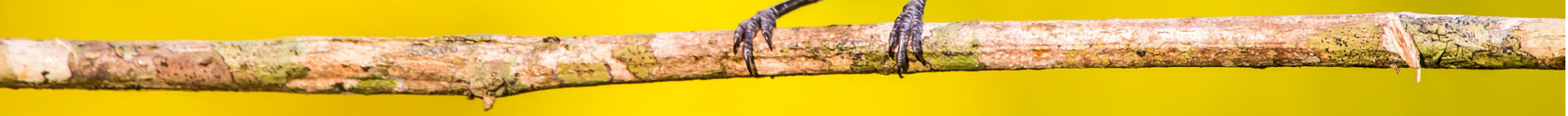




\section{Ações de Extensão para Gestão do Uso e Ocupação do Solo no Campus da Universidade Federal De Campina Grande em Pombal - PB}

Extension Actions For Management Of The Use And Occupation Of Soil In The Campus Of The Federal University Of Campina Grande In Pombal-PB

\section{Resumo}

O objetivo deste trabalho foi construir uma base documental para elaborar um zoneamento ambiental participativo com foco no uso e ocupação do solo no Centro de Ciências e Tecnologia Agroalimentar-Universidade Federal de Campina Grande, campus de Pombal-PB. Para isto, foram aplicados 372 questionários de composição mista, com dez perguntas de múltipla escolha e duas perguntas abertas, destinados à comunidade acadêmica e, concomitantemente, foi desenvolvido um diagnóstico de uso e ocupação atual do solo na área do CCTA-UFCG e da Fazenda Experimental pertencente ao Campus. Em sequência, construíram-se dois mapas temáticos e foram realizadas ações de extensão: elaboração e distribuições de folders e cartilhas referentes ao tema uso e ocupação do solo e uma palestra informativa sobre o andamento do projeto para a comunidade acadêmica. Os dados obtidos indicaram a necessidade de introdução e ampliação da temática "Uso e Ocupação do Solo" na área de estudo, pois a grande maioria dos atores da comunidade acadêmica do CCTA-UFCG não tem o devido conhecimento sobre o tema. Sendo assim, colocá-lo em pauta é um importante passo para mudar esta concepção, além de tornar a área de estudo uma referência no planejamento ambiental do uso e ocupação do solo, tanto para implantação ou ampliação de outras instituições de ensino e pesquisa, quanto para a sociedade local que, a princípio, será beneficiada indiretamente pela pesquisa.

Palavras-chave: Extensão universitária, Sustentabilidade, Zoneamento Ambiental.
Jonas da Silva Dias*

Ana Paula Fonseca e Silva

Andreza Maiara Silva Bezerra

José Cleidimário Araújo Leite

Maria Tatiane Leonardo Chaves

Universidade Federal de Campina Grande, Campus Pombal *E-mail: jonasuffg@hotmail.com 
The objective of this work was to build a documentary base to elaborate a participative environmental zoning with focus on the use and occupation of the soil in the Center for Food and Science and Technology of the Federal University of Campina Grande, campus of Pombal-PB. For this purpose, 372 mixed composition questionnaires were applied, where 10 questions were multiple choice and 2 open questions, destined to the academic community and, concurrently, a diagnosis of current land use and occupation was developed in the CCTA - UFCG and Fazenda area Experimental pertaining to the Campus. In sequence, two thematic maps were constructed, and extension actions were carried out: elaboration and distribution of folders and booklets referring to the theme of land use and occupation and an informative talk about the progress of the project for the academic community. The data obtained indicated the need to introduce and extend the theme "Land Use and Land Use" in the study area, since the great majority of the actors of the academic community of the CCTA - UFCG do not have the proper knowledge on the subject. Therefore, placing it on the agenda is an important step to change this conception, in addition to making the study area a reference in the environmental planning of land use and occupation, both for implantation or expansion of other teaching and research institutions, and to the local society, which, in principle, will benefit indirectly from the research.

Keywords: Environmental Zoning, Sustainability. University Extension. 


\section{INTRODUÇÃO}

O uso e a ocupação do solo são o reflexo de várias atividades econômicas responsáveis por alterar a qualidade do ar, da água, do solo e de outros recursos naturais, interferindo diretamente na qualidade de vida da população (PEREIRA; SANTOS, 2012).

O levantamento do uso e ocupação do solo é imprescindível para se analisar a forma pela qual determinada área está sendo ocupada, podendo servir para planejadores e legisladores visto que, ao se fazer esse levantamento, pode-se construir uma política mais correta de uso da terra para desenvolver a região (AMARAL; RIOS, 2012).

Para tornar mais evidente os padrões de uso e ocupação dos espaços é muito utilizado o recurso de mapeamento das informações. A visualização dos fatos no espaço melhora o entendimento das interações existentes e aponta as ações necessárias (SEBUSIANI; BETTINE, 2011).

Levando-se em conta a importância de compreender como se deu o Uso e Ocupação do Solo de determinada área e, também, em subsidiar planos futuros para a gestão da universidade, nesta pesquisa, apresentam-se os dados parciais referentes à vigência do projeto intitulado "Ações Estruturantes para Gestão do Uso e Ocupação do Solo" no período de maio a dezembro de 2016, pertencente ao "Programa CCTA Sustentável", que constitui uma iniciativa pioneira voltada à sustentabilidade em dez diferentes áreas no Centro de Ciências e Tecnologia Agroalimentar - CCTA, localizado em Pombal-PB, da Universidade Federal de Campina Grande - UFCG, sendo elas:

- Projeto 1 - Eixo Águas

- Projeto 2 - Eixo Resíduos Sólidos

- Projeto 3 - Eixo Energia

- Projeto 4 - Eixo Cultura e Memória

- Projeto 5 - Eixo Gestão de Pessoas

- Projeto 6 - Eixo Uso e Ocupação do Solo

- Projeto 7 - Eixo Comunicação

- Projeto 8 - Eixo Saúde

- Projeto 9 - Eixo Infraestrutura e Acessibilidade

- Projeto 10 - Eixo Alimentos

Nesse contexto, o estudo objetivou elaborar uma base para o zoneamento ambiental participativo com foco no uso e ocupação do solo no CCTA-UFCG, Campus de Pombal - PB. O público alvo deste trabalho foi, inicialmente, a comunidade acadêmica e, na sequência do projeto original, espera-se que outras instituições e repartições públicas e/ou privadas do município de Pombal e região venham a adotar as práticas e ações abordadas neste trabalho. 


\section{OBJETIVOS}

\section{Objetivo Geral}

Elaborar um zoneamento ambiental participativo com foco no uso e ocupação do solo no CCTA-UFCG, Campus de Pombal- PB.

\section{Objetivos Específicos}

- Elaborar um diagnóstico participativo de uso e ocupação do solo nas áreas do CCTA-UFCG e da Fazenda Experimental;

- Georreferenciar das diversas classes de uso e ocupação atual do solo em ambas as áreas objetos dessa pesquisa nas áreas do CCTA-UFCG e da Fazenda Experimental;

- Construir mapas de uso e ocupação atual do solo nas áreas em tela;

- Realizar palestra sobre a temática principal do projeto;

- Elaborar e aplicar questionários aos diferentes segmentos da comunidade acadêmica;

- Elaborar e distribuir um folder temático;

- Elaborar e distribuir uma cartilha temática;

- Mobilizar a comunidade acadêmica sobre os fundamentos e a importância da temática abordada no projeto.

\section{METODOLOGIA ADOTADA}

\section{Localização da área de estudo}

Este projeto foi desenvolvido no Centro de Ciências e Tecnologia Agroalimentar - CCTA, da Universidade Federal de Campina Grande - UFCG, Campus de
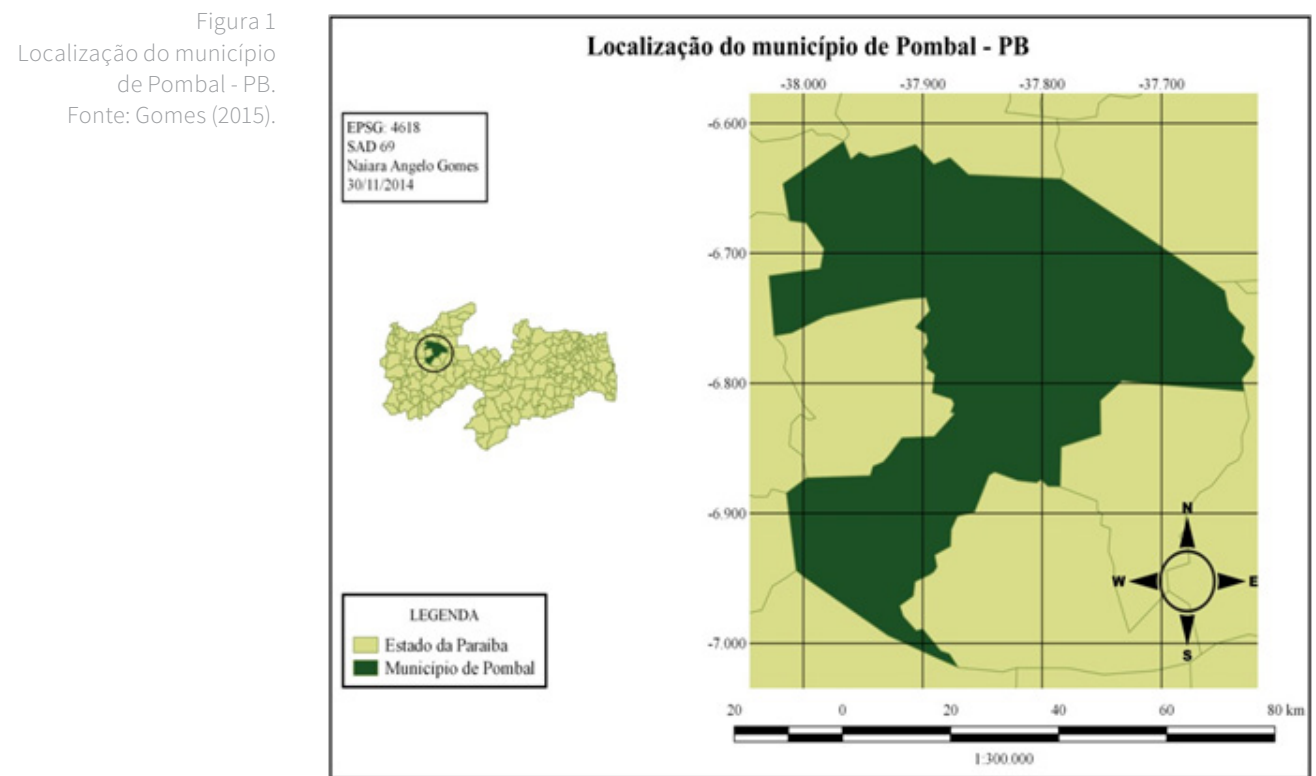
Pombal - PB. O município de Pombal (Figura 1) está localizado no estado da Paraíba, nas coordenadas geográficas $06^{\circ} 46^{\prime} 12^{\prime \prime}$ e $37^{\circ} 48^{\prime} 07^{\prime \prime} \mathrm{W}$, e situa-se na bacia hidrográfica do Rio Piranhas-Açu, entre a sub-bacia do rio Piancó e a região do Alto Piranhas (CPRM, 2005).

Segundo o Instituto Brasileiro de Geografia e Estatística (IBGE), em 2015 o município possuía área territorial de 888,807 km2 e, em 2016, população equivalente a 32.739 habitantes. O clima é do tipo Tropical Semiárido e a vegetação basicamente composta por Caatinga Hiperxerófila com trechos de Floresta Caducifólia; predomina o relevo suave ondulado, cortado por vales estreitos com vertentes dissecadas (CPRM, 2005).

\section{Diagnóstico Participativo}

O diagnóstico participativo foi elaborado em duas vertentes:

\section{Diagnóstico da percepção da comunidade acadêmica sobre a temática do projeto}

Essa etapa ocorreu entre os meses de julho a novembro de 2016; foram realizadas 370 consultas à comunidade acadêmica: 270 discentes, 33 técnicos administrativos e 67 docentes, para averiguação da percepção de cada segmento a respeito de fundamentos e importância do "uso e ocupação do solo" na área do CCTA/UFCG. A ideia foi aferir o grau de conhecimento e interesse da comunidade acadêmica acerca do tema objeto do projeto e assim construir a primeira parte do diagnóstico participativo.

A amostra (542 questionários) foi determinada com base na população de docentes, discentes, técnicos administrativos e servidores do campus (totalizando 1186 pessoas), em um nível de confiança de 95\% e uma margem de erro de 5\%, de acordo com o cálculo amostral proposto por LEVIN (1987), de acordo com a Equação 1, a seguir:

$$
\text { 1. } n=\frac{N \cdot \sigma^{2} \cdot\left(Z_{\alpha / 2}\right)^{2}}{(N-1) \cdot E^{2}+\sigma^{2} \cdot\left(Z_{\alpha / 2}\right)^{2}}=(1)
$$

Onde $\boldsymbol{N}$ é o tamanho da População, $\boldsymbol{Z}_{\boldsymbol{a} / \mathbf{2}}$ é o quantil da distribuição Normal padronizada ao nível $\boldsymbol{\sigma}$ de significância e $\boldsymbol{E}$ é o erro percentual admitido na pesquisa.

Os questionários destinados ao corpo discente da graduação possuíam 12 questões, e foram aplicados a 270 alunos, distribuídos a partir do $3^{\circ}$ período da graduação dos quatro cursos existentes no CCTA, sendo eles: Agronomia, Engenharia de Alimentos, Engenharia Ambiental e Engenharia Civil. Considerou-se que, a partir do terceiro período do curso, os alunos já seriam capazes de responder satisfatoriamente às perguntas requisitadas.

O cálculo amostral determinou que, para o público dos servidores docentes, a amostra corresponde à aplicação de 69 questionários distribuídos aleatoriamente entre os professores das três Unidades Acadêmicas do CCTA (Unidade Acadêmica de Ciência e Tecnologia Ambiental- UACTA, Unidade Acadêmica de Tecnologia de Ali- 
mentos- UATA e Unidade Acadêmica de Ciências Agrárias- UAGRA). Para este público, o questionário continha 13 perguntas, sendo 11 delas já existentes no questionário destinado aos alunos de graduação e consideradas "perguntas-chave" do tema, visto que continham questões relacionadas a conceitos básicos sobre uso e ocupação do solo. Foram acrescentadas poucas perguntas específicas aos docentes.

Os questionários aplicados aos técnicos-administrativos continham treze perguntas relacionadas ao tema, e assim como foi com os professores, o mesmo foi elaborado explorando as perguntas-chave sobre o tema e acrescentando perguntas que fossem pertinentes ao público. Neste caso as perguntas também diziam respeito aos conceitos básicos do tema. O valor amostral para este público foi de 33 questionários.

Os demais questionários, que a soma das suas amostras resulta em um total de 171 questionários, estavam destinados aos discentes de Pós-Graduação e aos servidores terceirizados do CCTA, porém, não se obteve êxito na aplicação com os mesmos, visto que não foi possível atingir o total da amostra especificado anteriormente e, portanto, não foram expostos os resultados para este público, sendo por enquanto retirados da pesquisa.

Com isso obteve-se, por fim, uma amostra de 372 questionários distribuídos proporcionalmente entre os docentes, discentes e técnicos administrativos.

Diagnóstico de uso e ocupação atual do solo nas áreas do CCTA/UFCG e da Fazenda Experimental:

Esta etapa foi desenvolvida por meio de consultas bibliográficas de publicações de 2006 a 2016, duas visitas a campo, elaboração do memorial fotográfico e utilização da ferramenta de geoprocessamento Qgis, a partir das quais foi possível elaborar mapas de uso e ocupação atual do solo, destacando-se as diversas classes de uso e ocupação atual do solo encontradas na área de abrangência do estudo. Essas atividades foram realizadas nos meses de maio e junho de 2016.

\section{Mapeamento do uso atual do solo no CCTA-UFCG}

Para a geração do mapa temático de uso atual do solo no CCTA-UFCG, foram realizadas várias atividades de campo, com o objetivo de se ter um diagnóstico atual simplificado da área em questão. Na obtenção dos dados georreferenciados (coordenadas geográficas), utilizou-se um Global Positioning System (GARMIN/GPSMAP 76CSX), necessário para identificação do posicionamento planimétrico da área de estudo e das diversas classes de uso do solo.

Ao se concluir as visitas de campo, passou-se à etapa seguinte que foi a confecção do mapa, realizada com o auxílio do software livre Quantum Gis (QGisDesktop 2.16.1), em que foram divididas as classes de uso atual do solo no CCTA-UFCG.

\section{Mapeamento do uso atual do solo na Fazenda Experimental}

Na criação do mapa temático de uso atual do solo da Fazenda Experimental do CCTA-UFCG, foram realizadas três visitas à fazenda experimental, de 30,50 hecta- 
res localizada no município de São Domingos - PB. Inicialmente, o objetivo principal foi observar as características do local e conhecer a situação atual da ocupação do solo. A etapa de obtenção de dados georreferenciados e de criação do mapa foi realizada a partir da metodologia utilizada no mapeamento da área do CCTA-UFCG.

\section{Ações de Extensão}

Palestra

A partir da etapa de Diagnóstico Participativo, que possibilitou conhecer a percepção da comunidade acadêmica com relação ao tema, foi realizada uma palestra intitulada "Uso e ocupação do solo: teoria e aplicações". A ação ocorreu no Miniauditório do CCTA-UFCG, em um evento intitulado: Primeiro Ciclo de Palestras do Programa CCTA - Sustentável, que contou com apresentações de três outros projetos do programa e palestrantes convidados.

A palestra foi elaborada e exibida no programa Microsoft Office Power Point (2007). Ela continha informações pertinentes ao tema de forma a expandir o conhecimento e diminuir dúvidas ou questionamentos e, ao mesmo tempo, apresentar a temática aos que ainda não a conheciam, expondo também os resultados parciais obtidos no projeto.

\section{Cartilha}

Foi confeccionada uma cartilha sobre uso e ocupação do solo com o auxílio do Microsoft Office Publisher (2007), com o intuito de fornecer e disseminar informações importantes sobre o uso e ocupação do solo, atendendo as carências identificadas na consulta sobre tal tema. Como forma de tornar a cartilha mais dinâmica, foram adicionados quadrinhos informativos, nos quais a plástica e inserção dos textos se deu por meio do Software Adobe Photoshop CS6.

\section{Folder}

Foi elaborado ainda um folder, construído por meio do programa "Microsoft Office Publisher (2007)".

\section{RESULTADOS}

\section{Mapa temático de uso atual do solo do CCTA-UFCG}

Realizaram-se visitas de campo na área do CCTA-UFCG com o objetivo de identificar os diversos tipos de uso do solo existentes no campus universitário, como por exemplo, áreas edificadas e com solo exposto, entre outras. Nas duas visitas realizadas foram obtidos registros fotográficos (Figura 2) e realizada a delimitação do perímetro da área. 


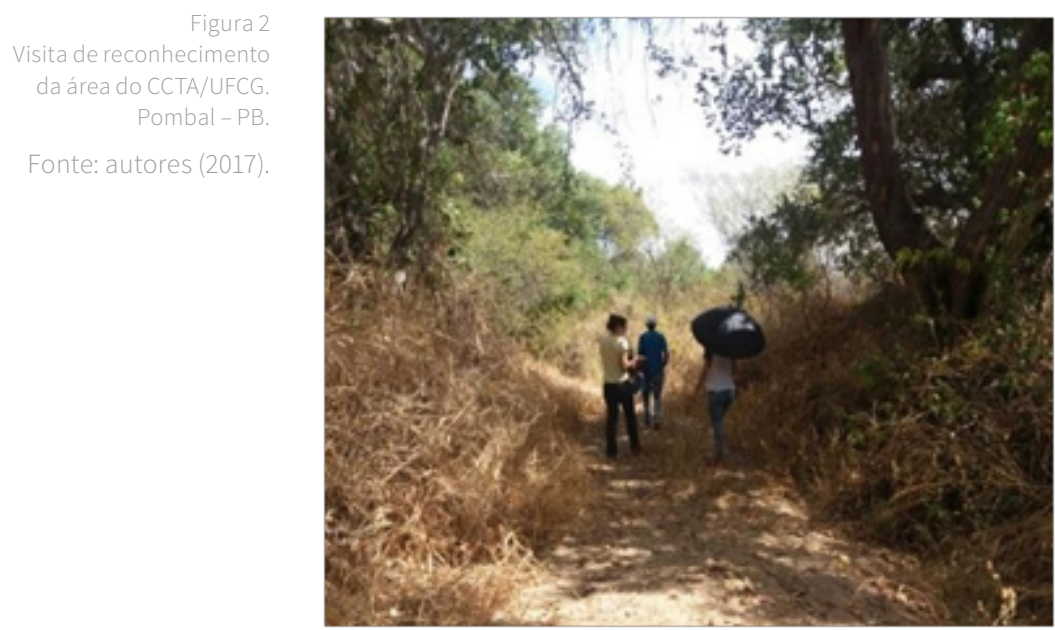

Após a análise dos dados obtidos, verificou-se que há duas classes de usos do solo predominantes no CCTA/UFCG: (1) de "vegetação nativa" e (2) "solo exposto", com cerca de $42 \%$ e $38 \%$, respectivamente. Os demais espaços são ocupados por áreas com vegetação urbana (arbórea e gramínea) com 10\%, 3,6\% de edificações, 3,4\% de áreas experimentais, 2,5\% de áreas pavimentadas e passarelas. Há também um riacho intermitente que atravessa a área do Campus, que equivale acerca de 0,5\% da área total, o qual na época da visita encontrava-se sem água, devido ao período de estiagem. Ressalta-se que a área total citada corresponde a 16 ha e o riacho intermitente a $800 \mathrm{~m} 2$ (0,5\%). Os valores das áreas das respectivas classes de uso do solo foram estimados de acordo com o mapa elaborado (Figura 3). a) mapa de uso e ocupação atual do solo no CCTA/ UFCG;

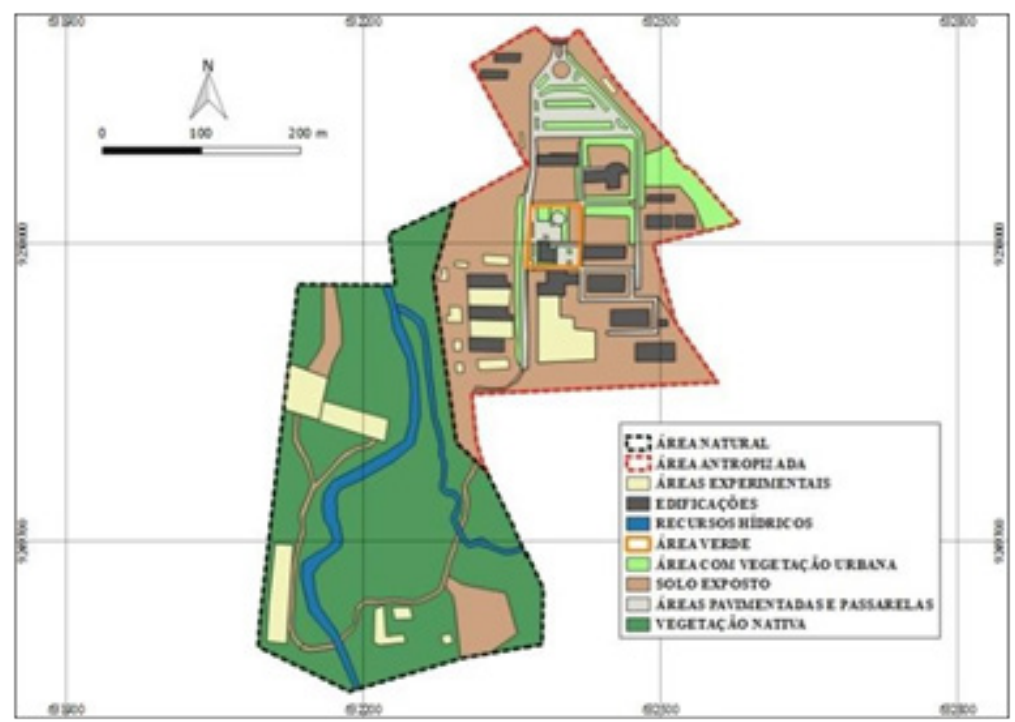




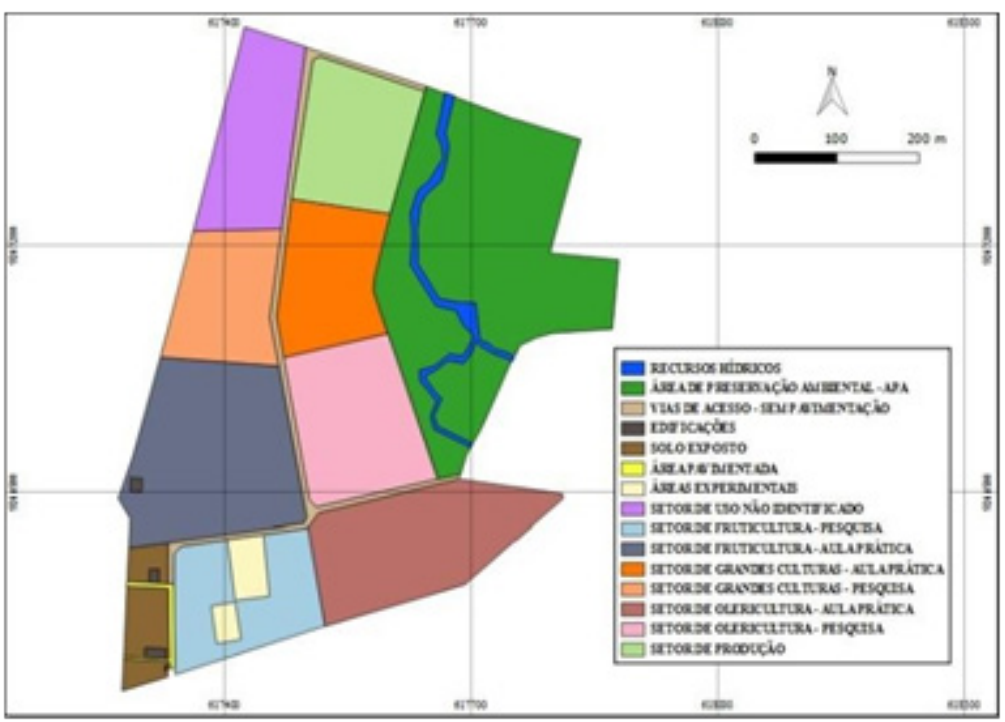

Figura 3

b) área ocupada pela Fazenda Experimental no mesmo Campus. Pombal $-\mathrm{PB}$

Destaque deve ser dado ao uso do solo na área natural, onde foram observados usos com áreas experimentais agrícolas, inclusive na Área de Preservação Permanente - APP, conforme dispõe o Novo Código Florestal Brasileiro - Lei n. 12.651 de 25 de maio de 2012. A referida APP é constituída pelas margens de um rio intermitente com largura de até $10 \mathrm{~m}$ que cruza o referido Campus. No CCTA-UFCG verificou-se a existência de uma área verde que apresenta em sua maior parte pavimentação e passarelas, áreas com edificações, solo exposto e uma porção mínima de áreas com vegetação urbana (Figura 3a), o que favorece, portanto, a redução da capacidade de infiltração de água no solo, devido ao revestimento superficial observado, ao contrário do que deveria haver nesse tipo de área. Há também a área da Fazenda Experimental (Figura 3b)

Após a confecção do mapa (Figura 3b), tornaram-se perceptíveis os quatro setores componentes da Fazenda Experimental: (1) Fruticultura, (2) Grandes Culturas, (3) Olericultura e (4) Produção para aulas práticas e pesquisas. No entanto, na maioria destes setores, ainda não foram desenvolvidas atividades. Isso ocorre porque a fazenda foi adquirida recentemente pela Universidade Federal de Campina Grande - UFCG e está em fase de instalação da infraestrutura física e experimental.

Entre os outros setores delimitados na área, destaca-se a Área de Preservação Ambiental. Esta área se encontra indicada por meio de placas e cercada no local, e contém no seu interior três riachos intermitentes. É uma área destinada pela Universidade para preservação e conservação, a qual segue os mesmos objetivos e princípios da Área de Proteção Ambiental, uma das Unidades de Uso Sustentável, previstas na Lei n. 9.985, de 18 de Julho de 2000 do Sistema Nacional de Unidades de Conservação da Natureza - SNUC. As demais classes de uso observadas foram: Vias de acesso, Edificações, Áreas pavimentadas, Solo Exposto, Áreas Experimentais (Ex- 
igura 4 - Realização da palestra sobre "uso e cupação do solo" no miniauditório do CCTA UFCG Pombal - PB.

perimentos em andamento) e uma Área de uso não identificado (que não tinha uma indicação ou identificação de destinação de uso, diferentemente dos outros setores).

\section{Ações de Extensão}

Palestra

Essa ação foi efetiva no miniauditório do CCTA-UFCG pelos discentes membros do projeto de extensão (Figura 4), e contemplou, de forma geral, os seguintes conteúdos:

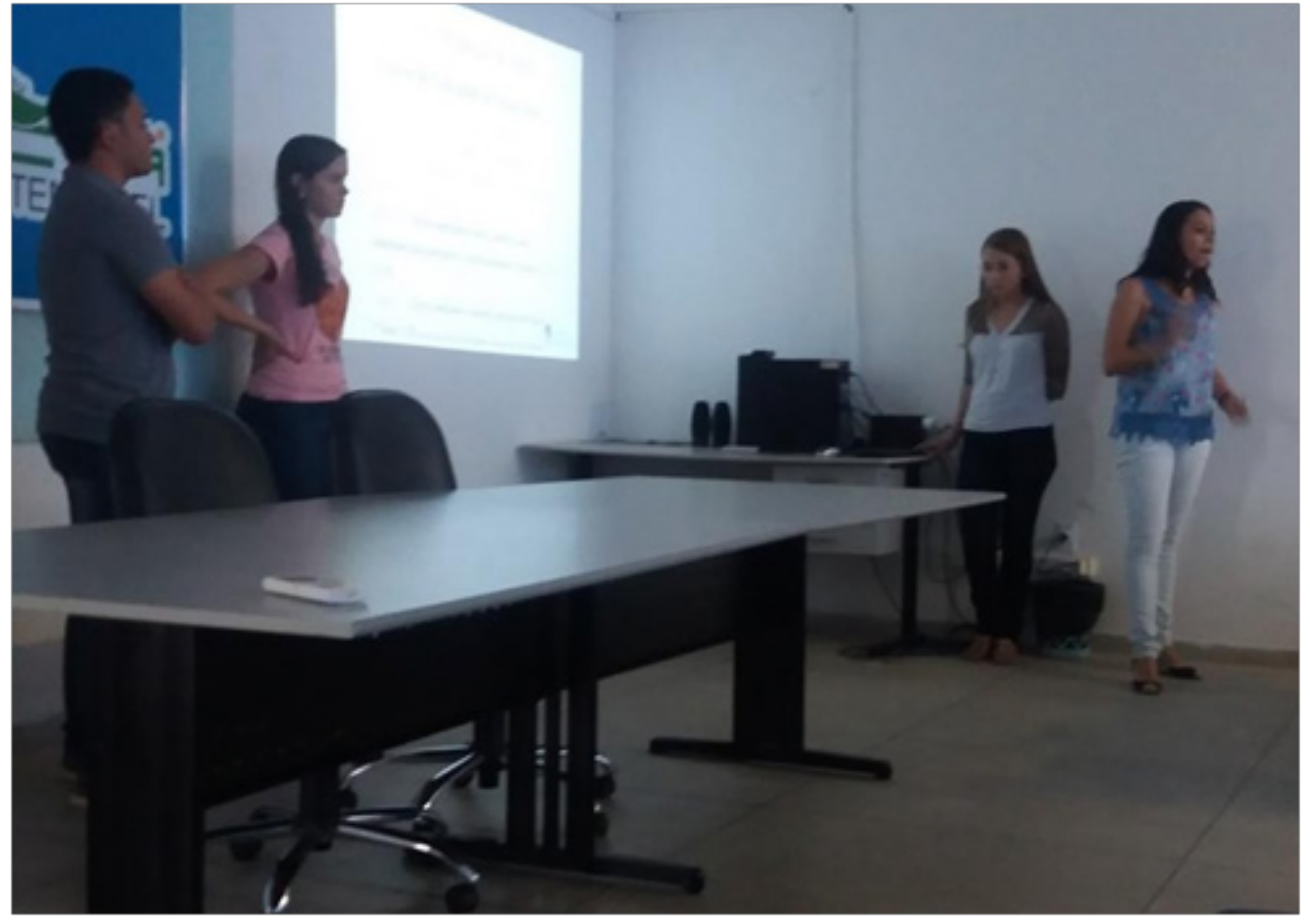

- O processo de ocupação do território;

- capacidade de uso do solo;

- consequências da ocupação inadequada do solo, e

- instrumentos de gestão do uso e ocupação do solo.

Também foi apresentado à comunidade acadêmica um conjunto de informações sobre o projeto de extensão, incluindo parte dos resultados obtidos até então: a produção dos mapas do Campus e da fazenda experimental; o diagnóstico da comunidade acadêmica sobre conhecimentos relativos ao tema do projeto e a produção e distribuição de folders e cartilhas com informações relevantes sobre uso e ocupação do solo, além de ações futuras a serem realizadas no projeto como, por exemplo, a indicação dos usos do solo de acordo com suas características. cartilha

As informações inerentes ao projeto de uso e ocupação do solo em desenvolvimento no Campus foram alocadas em uma cartilha e em um folder, para melhor 
disseminação dos conteúdos relacionados e divulgação do projeto, que foram distribuídas pela equipe responsável pelo projeto (Figura 5).
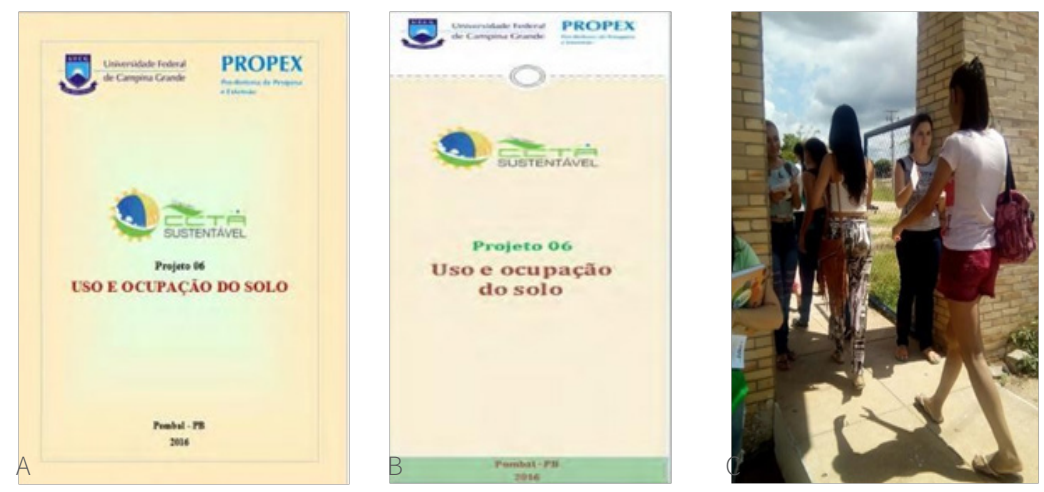

Figura 5

a) capa da cartilha elaborada; b) capa do folder; c) momento da distribuição de ambos. Pombal - PB.

A cartilha apresenta informações gerais sobre o programa CCTA sustentável; o projeto "uso e ocupação do solo", assim como informações relevantes sobre o tema em questão. Também foram disponibilizados os mapas do campus e da fazenda experimental para informar à comunidade acadêmica as condições de uso atual do solo na área de estudo, que servirão de base para um planejamento das ações futuras.

Ademais, a cartilha contém elementos visuais, como imagens e quadrinhos, que tornam a leitura mais atrativa para o público-alvo (servidores técnicos e docentes do setor administrativo e gestores do CCTA-UFCG), bem como fornece e dissemina informações importantes sobre o uso e ocupação do solo, e atende as carências identificadas na consulta sobre este tema.

\section{Folder}

O conteúdo do folder é constituído, de forma geral, por um resumo da cartiIha (elementos visuais em forma de fotos ilustrativas), aborda o tema uso e ocupação do solo, e traz os mapas do campus e da fazenda experimental. Este material informativo foi distribuído na comunidade acadêmica em maior quantidade em relação à cartilha, para trazer informações sobre o tema em questão e atender parte das demandas identificadas a partir da análise dos dados obtidos na consulta ao público alvo do estudo.

\section{CONCLUSÕES}

As atividades desenvolvidas durante a vigência do Programa CCTA Sustentável, em particular neste projeto, foram de grande relevância para a comunidade acadêmica. Os objetivos do projeto de extensão foram atingidos através dos diversos conhecimentos transmitidos por meio das ferramentas educativas utilizadas e serão importantes para a formação profissional dos discentes dos cursos de graduação do referido campus (Agronomia, Engenharia Ambiental, Engenharia Civil e Engenharia 
de Alimentos), bem como para os demais membros da comunidade acadêmica.

Pela análise dos dados verificou-se a necessidade de ampliação da temática "Uso e Ocupação do Solo", devido aos problemas apresentados, em que se mostra uma falta de concepção sobre o tema. O fato é que colocar este tema em pauta é um importante passo para a formulação de um novo conceito, além de tornar o CCTA/ UFCG uma referência sobre o tema, tanto para a sociedade como para outras instituições de ensino fundamental, médio e principalmente superior.

Por fim, espera-se que este tema seja amplamente debatido nas diversas Instituições de Ensino Superior - IES disseminadas pelo país e que o uso e a ocupação do solo venham a ser realizados de forma planejada nas áreas pertencentes ao CCTA/UFCG, Campus de Pombal - PB, de forma a reduzir os impactos causados pelas intervenções e melhorar a qualidade de vida das pessoas, além de contribuir para a sustentabilidade.

\section{REFERÊNCIAS}

[1] Amaral, A. B; Rios, A. S. Geoprocessamento: mapeamento de uso e ocupação do solo no alto curso do rio Piedade. Revista de Geografia- PPGEO, v. 2, n.1, p. 1-8, 2012.

[2] Brasil. Lei no 12.651, de 25 de maio de 2012. Dispõe sobre a proteção da vegetação nativa; altera as Leis n. 6.938, de 31 de agosto de 1981, 9.393, de 19 de dezembro de 1996, e 11.428, de 22 de dezembro de 2006; revoga as Leis n. 4.771, de 15 de setembro de 1965, e 7.754, de 14 de abril de 1989, e a Medida Provisória no 2.166-67, de 24 de agosto de 2001; e dá outras providências. Disponível em: < http://www.planalto.gov.br/ccivil_03/_ato20112014/2012/lei//12651.htm>. Acesso em: 12 de dez. 2017.

[3] CPRM. COMPANHIA DE PESQUISA DE RECURSOS MINERAIS. Projeto cadastro de fontes de abastecimento por água subterrânea. Recife: CPRM, 2005. (Diagnóstico do município de Pombal-PB). Disponível em: <http://rigeo. cprm.gov.br/xmlui/bitstream/handle/doc/16266/REl_Pombal.pdf?sequence=1>. Acesso em: 27 dez. 2016.

[4] Gomes, N. A. Avaliação dos impactos ambientais causados pelo "lixão" de Pombal-PB. 2015. 81 fls. Trabalho de Conclusão de Curso (Graduação em Engenharia Ambiental) - Unidade Acadêmica de Ciências e Tecnologia Ambiental, Universidade Federal de Campina Grande, Pombal-PB. 2015.

[5] Levin, Jack. Estatística Aplicada a Ciências Humanas. 2. ed. São Paulo: Harbra, 1987.

[6] Paraíba Ibge 2012. Disponível em:

<http://cidades.ibge.gov.br/xtras/perfil.php?lang=\&codmun=251210\&search=paraiba|pomballinf ograficos:informacoes-completas>. Acesso em 24 jan. 2017.

[7] Pereira, A. K. C; Santos, L. O. L. Dos. Mapeamento dos tipos uso e ocupação do solo da região do centro da cidade, Santa Inês- MA. In: CONGRESSO NORTE E NORDESTE DE PESQUISA E INOVAÇÃO, VII, 2012. Palmas. Anais Eletrônicos... Palmas-TO, 2012. Disponível em:

<http://propi.ifto.edu.br/ocs/index.php/connepi/vii/paper/viewFile/1118/2114>. Acesso em: 30 jan. 2017.

[8] Sebusiani, H. R. V; Bettine, S. C. Metodologia de análise do uso e ocupação do solo em micro bacia urbana. Revista Brasileira de Gestão e Desenvolvimento Regional. Taubaté, v. 7, n. 1, p. 256-285, jan/abr.2011.

[9] Serviço Geológico Do Brasil (CPRM). Projeto Cadastro de Fontes de Abastecimento por Água Subterrânea: Diagnóstico do município de Pombal. Recife: CPRM/PRODEEM, 2005. 23 p. 


\section{AGRADECIMENTOS}

À Universidade Federal de Campina Grande (UFCG), em especial ao Centro de Ciências e Tecnologia Agroalimentar (CCTA).

À Pró-Reitoria de Pesquisa e Extensão (PROPEX) e ao Programa CCTA Sustentável. Ao Professor José Cleidimário Araújo Leite, orientador deste trabalho. 